\title{
Problems in Public Sports Service and Their Solutions
}

\author{
Quan Xu and Xuanjie Zhou
}

NanChang Institute of Science and Technology, Nanchang, 330108

Keyword: Public sports; Public service; Problems; Solutions

\begin{abstract}
The system of public sports service is an institutional arrangement which is carried out by governments to guarantee citizens' basic right of sports and the fundament of motivating the coordination of sports and the sustainable development. Based on the sketch of researches related to the system of public sports service, the guiding idea and basic principles of building the system of public sports service have been come up with in this essay. The basic framework of the system of public sports service in our country has been constructed in four aspects of the basic principle problems of system of public sports service, the public sports products, providing service, the operating process of public sports service, the efficiency of public sports service and the sustainable development. Besides, several pieces of advice about practicing the system of public sports service have also been given.
\end{abstract}

\section{Introduction}

In recent years, as the cause of socialism with Chinese characteristics has made a great progress, people's requirements to living standard have gone higher. As one of the important criteria of living standard, fitness shows its significance meaning to build a stronger country, which has been raised to a national strategic goal. In our country, governments are strengthening of guiding and rules to promote the development of mass public sports, which has achieved an obvious improvement. In this essay, the raising of mass public sports service was deeply analyzed, and the problems we are facing with when constructing mass public sports service, based on which the solutions to raise the level of mass public sports service to promote the development of mass fitness and the physical qualities of our citizens.

\section{Development of Public Sports Facilities in Our Country}

Public sports facilities are built to satisfy the mass need of sports. In general, public sports facilities are invested by governments, organizations or individuals to provide places for people to do exercises, entertain themselves. Currently, the management of public sports is depending on sports administration to invest and maintain. It has been written in Budget Law of People's Republic of China that budget of expenditure should include the expenditure in the fields of education, culture, sanitation, sports and so on. In the budget of developing sports, there is an allowance for mass public sports place to manage and maintain it. In Sports Law in People's Republic of China, there is rule about maintaining the public sports facilities, it is: "Governments beyond town should add the expenditure of sports and the fundamental construction of sports to local financial budget and basic investment plan, and they should invest more as the development of GDP.

People who behave as above and disobey security administration will be disciplined by regulations regarding public order administration. People who commit crimes will be given criminal sanctions. It is showed in the law of public sports facilities and the budget for sports that our country values the development of mass public sports. The construction of public sports facilities is a symbol to judge the development of a country's sports, and is also a protection of citizens' sports right. 


\section{Problems of the Development of the Mass Public Sports Service}

Social Sports Organizations Are in Short, and the Fundamental Organizations Are Weak. China's total population base is relatively large, and sports associations are relatively few, which make our country's community organizations cannot consider every citizen, and community organizations do not have a good sports public service. In addition, China's grassroots fitness organization is also very weak. These organizations often in situations of organizational structure confusion and irregular. Grassroots fitness organization as a spontaneous grassroots organization has a positive significance for the development of national fitness.

The Mass Public Sports Services Are Mainly Provided by Governments, and Lack the Methods of Marketing and Cooperating. In China, the allocation of sports resources is mainly based on the supply of government, through the top-down form. This kind of administrative mechanism, although can do good to carry out public sports services in a short period to speed up the development of national fitness and to achieve rapid construction results in a short period, but it is not conducive to the sustainable development of public sports services. Only some developed cities have adopted a cooperative, market-oriented supply, and most of cities' mass public sports service mainly rely on the government's executive order. The development of mass public sports service is given financial support through the government's financial subsidies, which, to a certain extent, limited the development of mass public sports service.

The Information of Mass Public Sports Services Is Legged Back, and the Data of Which Is not Enough. In recent years, our government is actively upgrading the information infrastructure, and to ensure the sending of public service information through the public network. In order to promote the mass public sports service, some local governments in our country have set up the mass public sports service information platform, but the content of public information platform is limited to the publicity of mass public sports, and it is not a comprehensive information platform which is integrated with resource sharing and national communication, and it cannot arouse people's interest in using information platform to participate in fitness. The phenomenon of information of mass public sports service lagging and data lacking are very common, affecting the development of the mass public sports service.

\section{Solutions to the Development of the Mass Public Sports Service}

Although progress have been made in mass public sports service these years, there're still many problems need to be handle to promote the development of mass public sports service.

Strengthen the Construction of Organizations of Mass Public Sports Services, and Perfect the Network of Fitness gyms. The development of mass public sports cannot be separated from the perfection of mass fitness network. We need to pay attention to the important role of social organization to guide people to physical fitness. To strengthen the construction of social organizations for all people, the following three aspects are needed: First, actively promote the socialization and marketization of social organizations and provide continuous financial support to social organizations through effective business activities. Second, construct sports associations like sports association, and meanwhile pay attention to the construction of informal social organizations, through the form of voluntary services, let the sports elite participate in it. Third, strengthen the provincial, municipal and county level organization, give full play to the role of different levels of organization, to establish a multi-sectoral network of fitness organizations.

Discipline the Supervision of Constructing Sites, Meanwhile Promote the Development of Information. The development of mass public sports cannot be separated from effective supervision and management, for this reason, the government provides policy and financial support for the mass sports organizations, and in accordance with the situation of sports organizations in different areas, government also establishes the rules of the development of norms. The establishment of sports organizations must be audited and approved by relevant departments, at the same time the government has also launched a "fitness site information interactive system" to improve the level of information on fitness sites. 
Perfect the Facilities of Mass Public Sports, and Build Fitness Facilities with Local Characteristics. At present, the mass public sports facilities in various regions cannot meet the needs of local residents, and to solve it, the government is increasing the investment in related funds. Show a local characteristic in the setting of mass public sports facilities, add the proportion of sports equipment, and use local conditions of the surrounding environment to build sports facilities with regional characteristics. Encourage running, qigong, gymnastics and other sports projects. Construct regional characteristics of the operation of the project to improve the physical qualities of the masses.

Make the Construction of Mass Public Information Service Network Faster. In order to improve the service ability of public information, it is necessary to speed up the construction of public information service network. To construct it, the government should focus on the construction of system platform and basic database, in which the system platform is mainly used to achieve fitness guidance, public management, data docking and other functions, to provide efficient and convenient service for masses, and the basic database is mainly responsible for sports settings, grass-roots organizations, organizational activities, other data information. In addition, government should encourage citizens to actively give advice for the development of mass fitness on the internet platform, to achieve universal participation.

\section{Conclusion}

The weak point of our public sports facilities reflects a fact that the public sports facilities are not under effective management and supervision for a long time, and the investment from country is not enough so that the construction and management of public sports facilities are not systematized, which call for China to value the construction and maintain of public sports facilities. As our country's economy and the urbanization level going up rapidly, the need of sports facilities and residents' leisure time is raising. It is its right and obligation to meet citizens' demand of exercising. Since the total population base in China is large, it's hard for government to meet the demand of billions of people, which means that companies and individual should be encouraged to invest the construction of public sports facilities, and form a long-term mechanism. Governments' macro management and individuals' specific management should work together to match the relative policy of China to strengthen the development of public sports facilities. Start from practice, strengthen management and maintain. Provide us with a safe, comfortable public sports environment.

\section{References}

[1] Xiao L P. The Concept and Construction of Chinese Public Sports Service System[J]. Journal of Xian Physical Education University, 2008.

[2] Yoo, HanWoong, Kang, et al. Study on the Correlation Between the Financial Conditions and the Business Performance of Public Sports Service Organizations[J]. Korean Journal of Physical Education, 2017, 56.

[3] Chao-Hui D U. On the Characteristics of Demand of Public Sports Service and Innovative Supply Countermeasures in Western Rural Area[J]. Journal of Guangxi Vocational \& Technical College, 2017.

[4] Xiao L P, Zong-Hao L I, Yang X C. On the Conception and Theories of Public Sports Service[J]. Journal of Tianjin University of Sport, 2007.

[5] Sport Science Research, 2009.

[6] Wang B C, Fan D Y. Background of Public Sports Service Reform in Developed Countries and Its Enlightenments[J]. Journal of Shanghai University of Sport, 2010.

[7] Cai-Xing J. Establishing a Perfect Sports Public Service System[J]. Sport Science Research, 2008.

[8] Pan X M. Ideas and Goals of Public Sports Service Development[J]. Journal of Shanghai University of Sport, 2010. 
[9] Wang C X. Practice and Exploration of Shanghai Sports Public Service[J]. Sport Science Research, 2008.

[10]Cui R, Su L. Research Status on Equalization of Public Sports Service for Nationwide Fitness in Hebei[J]. Physics Procedia, 2012, 25:2298-2303.

[11]Wang Q. Research on Public Sports Service in Higher Learning Institutions[J]. Journal of Shanghai University of Sport, 2010.

[12]Zhang L I, Tian Y P. Status Quo and Countermeasure of the Equalization of China's Sports Public Service[J]. Journal of Xian Physical Education University, 2010. 